\title{
Thought Provokers, Insurgent Before Emergency —-Technological Art as Awareness-Raising Agent of the Emancipated Spectator
}

\author{
Alejandra Elena Marinaro, Romina Alicia Flores \\ School of Communication and Multimedia Design, Universidad Maimónides, Buenos Aires, Argentina
}

\begin{abstract}
This paper analyzes the impact of technological art as an agent for raising awareness in artwork spectators of ecological-environmental issues. It addresses the evolution in the conception of the artistic fact related to science, and attempts to define the spectator's new role. The present document will look into the science, art and technology triad as a means to communicate issues our planet is facing through scientific dissemination focusing on the bio-art avenue for collaboration. Finally, we will outline our concept of art as a revolutionary and thoughtful form poured through our works as artistic collective expressions.
\end{abstract}

Keywords: bio-art, science, technology, interactive installations, interactive design, education, digital art, creativity

\section{Introduction: The Evolution and Revolution of Art}

In the last decades of the twentieth century, artists initiated a search for new methodologies, new languages and new materials in order to find the answers to the one question that human beings have been making since ancient times: what is their relation to nature?

Throughout the 1960s, artwork started to be developed as of elements in nature. This was indeed the beginning of the so-called Land Art, using the natural environment as support for the works.

Its purpose is mainly to influence space in nature without causing any damage, yet providing it with meaning as an aesthetic fact.

Unlike other artistic trends, Land Art lacks all sort of explicit manifests. It is therefore possible to find as many exponents and examples of Land Art as particular relations established between artists and nature itself there may be. Being contemporary to our time, it is difficult to set well-differentiated boundaries in terms of other types of art or of artistic genre, thus obtaining many interventions close to performances, body art or action art—also known as life art.

However, it is still possible to trace a guiding principle among all artists when contemplating nature and the physical plane as a process or artistic fact, discarding the notion of art as mimesis or as a romantic ideal.

Most of the artistic production rendered in the second half of the twentieth century owes its existence to the guidelines set forth by Marcel Duchamp (1887-1968) and his ready-made, which opened up the field of

Alejandra Elena Marinaro, Public Accountant, Universidad de Buenos Aires; Master of Business Administration, Universidad del Salvador, Argentina \& Universidad de Deusto, Spain.

Romina Alicia Flores, Graphic Designer, Facultad de Arquitectura, Diseño y Urbanismo de la Universidad de Buenos Aires. 
what had been so far considered art.

On placing objects of daily use in a new context, he made traditional precepts within the world of art, such as beauty—idealized since ancient times_or the value ascribed to the "hand-made" category, shake.

The new meaning ascribed to these objects - in which not only an aesthetic value is found, but also a system of symbols emerges through a message that calls out for "some additional point to make"-, will all be inception matters for the development of many currents that will surface in the future. Among these stand Pop-Art, where popular images become cultural or counter-cultural icons; Poor or Impoverished Art, which uses waste objects as main materials to cast new light and counterweight traditional culture, considered inalienable and closed to the exploration of new revolutionary perspectives.

These expressions come to life, too, as part of the tradition of artists that learn about and document their environments. Climate change, alterations in soil and in the level of waters, the extinction of flora and fauna species in different locations of our planet due to the predatory behavior of men, all call for the necessary and urgent emergence of a type of art that may attempt to send out a warning message and to raise awareness-a new and unexplored concept, since natural resources were once thought to be unlimited and inexhaustible. Both land art and impoverished art find in real life the perfect matter for artwork, casting aside previously established ideas such as the eternal nature of art, and giving birth to works that may be ephemeral, leaving behind only traces that are foreign to the artwork itself, as is the case of photography or video recording. This conceptual process presents us with the implications of art vis-à-vis life in its natural environment, as we have seen.

A simple answer to this issue-yet a difficult one to implement-area radical change of mind and a new approach to address environmental decline. This may well begin through a human expression that may assimilate predation, yet using the existing and disposable material to send out an emergency alert that may reach active recipients, capable of incorporating small yet meaningful modifications into their daily lives-reutilization, recycling, technological waste control, saving on the use of paper and all forms of responsible consumption - in order to halt environmental destruction. Land art and impoverished art make it possible to infer that in addition to it being an aesthetic and cultural fact, life is art.

The arrival of technological art raises awareness of the environmental situation from a different perspective and understanding of the world per se. Pollution, relentless logging of native forests, the invasion of natural environments without any type of control by the states, these are all recurrent themes in paintings, sculptures, photographs, videos, facilities and interventions. Numerous works by technological or multimedia artists show concern over the state of the planet and put forth an invitation to reflect upon the attitudes of mankind. In the same fashion, many of these works also bring forward a set of competencies to offer positive alternatives for environmental preservation.

This sort of intertwining between art, culture and nature through creative paths is another way of exerting perseverance on our efforts to improve the human relation with ecosystems across the planet.

\section{Bio-art as a Cell Transcending From Micro to Universal}

As of the scientific discoveries of the past century, the way we perceive, interpret and understand reality is still undergoing an historic alteration.

Science, technology and art, anchored in a society equipped with and yet providing all sorts of networks that interrelate with each other and allow for communication amongst individuals, cease to be watertight compartments detached from the vital experience of subjects in order to extend their frontiers until finding 
points of contact and give way to a multi-disciplinary vision for comprehending life, no longer as a single experience, but rather as an educational, and aesthetic phenomenon calling for research.

The birth of bio-art as an artistic practice appears as an exponent of this interrelation, leaving the typical environment of the artist aside, in order to get into and actively participate in biotechnology labs, using methodologies that apply to the realm of biological sciences, and relate to the handling of live matter. This new practice is exposed to the issues and the questions that artwork has always triggered, related to the living experience of the subject immersed in a particular society and in a specific moment in time. Its herald, Eduardo Kac, developed his work as of the subject's position in the post-digital world, questioning the evolution, the memory and even the condition of creation, and posing the need for reflection upon the scientific developments within an ethical and social standpoint, creating a critical context in which to carefully examine the biological practices and thus weaken the reductionist ideas and eugenics in particular.

In order to clearly explain the relevance of the emergence of bio-art in the artistic scenario, it is necessary to read the implications of the experiences as a scientific experiment, verifiable and with provable results, as opposed to the experience related to the subjective plane in terms of the individual's capacity to take in and enjoy the aesthetic fact.

The work of bio-art is understood as a scheme made of different scientific developments that allow for a set of experiences. It has the capacity of enhancing interaction between the artistic experience and the scientific experience, without becoming an object with the sole purpose of being contemplated, but rather of recreating a truly groundbreaking experience.

On the one hand, bio-art allows for rethinking science and art as a joint collaboration, as watertight compartments many a time separated throughout the history of mankind, which may not be subordinated, which complement each other, and which trigger reflection on the available technological devices, their scope and impact, and potential for development.

On the other hand, it is of vital importance to pinpoint the capacity inherent in bio-art for working with live organic matter, ranging from a cell—understood as the minimum portion an organism may be divided into- to the full body that hosts all of the cells and tissues.

This living art shows specific aesthetic features as it holds a close connection with the sciences. In this sense, bio-art sharpens the crisis found in traditional aesthetics on introducing works that pose variable transformations and a transient nature. In light of this definition, we must highlight its conceptual character-experimental as a contemporary work of art-, which being introduced as a fleeting event, can indeed overcome its material nature. Yet, it also establishes different relationships with the environments in which it is exhibited, the feedback from critics, the manifests. For the above stated, we could assert this to be a work in constant mutation. At this point, we can only address it as a work in continuous state of convergence and evolution, thus making the public's participation key to attain the whole artistic experience.

\section{The Role of the Spectator: Emancipated Spectator and Moved Spectator}

"Upon insisting on the problematic and open nature of every artistic proposal, on seeking the expansion of creativity through the reconciliation of art and life, the cutting-edge trends underpinned the creative dimension in our cultural tradition implicit as never before in the response to the artwork.

In a text dated 1957, precisely entitled "The Creative Process”, Marcel Duchamp remarked the following, "the artist is not the only one consummating the creative act, as the spectator establishes the contact between the work and the outer 
world, untangling and interpreting his own ratings to make his own contribution to the creative process.”

This conception, which presupposes a thorough rethinking of the romantic myth in the virtuous and different mind of the artist along with the acknowledgement of the anthropological universality of creativity, would signal as of the 60s a new understanding of the role of the public in the creative transmission of art. (Jimenez, 1998)

The change of paradigm in art and the opening of unconventional spaces for the exhibition of the works, paved the way for a logical change in the role of the spectator.

After centuries of contemplative education in front of the artistic expression, limited by the pedestal in the case of sculptures and the frame in the case of pictorial art, the spectator is invited to participate, interact and complete the work.

With the emergence of the new category of interactivity, the works are from their very inception aimed at the spectator.

This change paves the way, particularly in the case of technological art, for bringing the spectator closer to new knowledge and developments, both in the technical and scientific fields that had been locked away for centuries in laboratories, only to reach the expert eye.

In this sense, the spectator is not only invited to intervene in the real-time production of the artistic fact, but also given the added value of new knowledge for him to reflect upon the novel pieces of information he obtains. And although the artistic fact represents an end in itself, it can at the same time be considered an excuse to outline and theorize on the pressing issues of life, the ecology and the environment.

In this respect, Bourriad states that "reality is that which I can talk with someone else about" (1998, p. 56). Therefore, these works that defy the passive nature of the typical spectator, force him to forget the mechanical task of observation, and share a new communication code. For this to happen, it is necessary for the new spectator of the artwork to decide to adhere to the new strategies that the work of art presents him with. It is not just a matter of taking a moment to look at it, take some distance and observe again. The spectator is asked to perform the art exhibition just as Duchamp would remark. This is not only evinced in the interpretation or the theoretical construction, but also in the material level at which the spectator constitutes himself as a key player in the artistic phenomenon to be revealed.

In this way, the category of interaction takes over that of participation, finally overcoming the traditional distance artist-work-public phase.

In this sense, as of the dialogue generated between those involved in the creation of the artwork and the spectators invited to join in, a new form of reconciliation is achieved as of the experience. This type of involvement, many times unconscious on the part of the spectator, bears an impact on his way of perceiving the world around him. Contrary to what happened centuries ago, where art also played an educational role, but could only be adhered by the artistic genius, the works and artistic devices also provide the social body with a number of strategies and technical developments ranging from very simple forms to high complexity advances, which allow for adoption of artistic models present in technological artwork at a small scale, and incorporate them throughout time in daily life.

Thus, art also grants visibility to certain technical strategies that may serve in the near future the development of goods and services along with the environmental conservation strategies.

And upon involving the observer himself in the construction of the aesthetic object-mainly because as of this moment onwards, poiesis presupposes a process in which the preceptor becomes co-creator of the work, art frees the 
aesthetic response or reaction from its passive and contemplative nature. This is clearly the straightforward meaning of the exclusive hermeneutics maxim so unfairly discussed: mes vers ont le sens qu'on leur prete

[...] Being the de-objectification completely exhausted, the aesthetic status becomes a problem, and the spectator, faced with an objet ambigu, finds himself again in the situation of asking if said object may have the right to be-in spite of, or also-, art. (Jauss, 1986, pp. 108-110)

\section{The Science, Art and Technology Triad: Scientific Dissemination and Raising Awareness}

The spheres of art and knowledge have been historically related, both to differentiate each other and to find points of shared interest. Their changes have been in consonance with the times in which they have developed. As of the scientific revolution that took place in the seventeenth century, the different standpoints started to come together, paving the way for a future interaction between art and science, and establishing a differentiated and legitimate speech for each and every field. In the nineteenth century, what is known today as modern science was defined, along with the figure of the artist as an individual creator. At the turn of the twentieth century, art and science were further specialized in their fields, making contributions in both realms, implying parallel findings for artists and scientists.

Modernity developed both artistic and scientific proposals that evince trust in the human possibility of knowing, learning and ordering the world from the active subject’s standpoint. (Suárez Guerrini, Gustavino, Correbo, \& Matewecki, 2010, p. 16)

As of the scientific and technological developments that took place in the last fifty years, the way art is created has once again changed what we used to know about it. We can trace this in the advent of the notion of plurality of real worlds, both diverse and valid, with their well-differentiated systems of reference, working jointly to leave their familiar environments behind and get the public closer to multi-disciplinary developments. The proper arena for research, experimentation and production of the works is the laboratories. This implies the use of science-specific techniques, methods and protocols. However, both in the realm of art and in those of science and technology, the guiding principle of finding an answer to every question in life leads to the convergence of lexicon, procedures and materials. Thus, artists working along with scientists and technicians bring the subjective eye closer to the objective fact, and then home to the result. They find the way to summarize the conclusions arrived at after laborious research and findings, to turn these into a metaphor of some sphere of life.

Art is then the most appropriate vehicle to go beyond the laboratory and become known in the world. Thus, what would have only been accessible to the scholar or learned person is now presented to the individual as a fictional reality capable of being comprehended, reflected upon and conveyed to others.

In a scientific dissertation, literal truth plays a key role, yet in a poem or in a novel, metaphorical or allegorical truth may carry more weight, since a literally false statement may be metaphorically true. (Goodman, 1990, p. 39)

The close relation between artists and methods, and processes in science causes the appearance of new characters, such as the scientist-artist, the researcher-artist or the teacher-artist.

During times of crisis of the fundamentals of art, the boundaries of the artistic become blurred and give way to aesthetic reconfigurations that also trigger ethical debate over life and the impact of men's actions on all living things. 


\section{Sensory Experimentation as a Way to Awareness Raising and Reflection}

Climate change, intervention of nature, assisted fertilization of botanical species, hydraulic emergency, and extinction of species: the actions of men over nature for its destruction or reconstruction have been the common denominator that has linked the artworks of Project Untitled since its inception in 2006, in the milieu of Universidad Maimónides.

This cross-disciplinary ensemble of artists, professors, students and scientists carried out over a dozen multimedia works in which the technology—nature dichotomy has been always at play.

The artistic ensemble has played a major role since its early beginnings, being the maximum exponent of interrelation with other areas of knowledge. In fact, in a matter of a few years of joint collaboration, Project Untitled has been able to incorporate biological elements into its productions. Scientists, artists and researchers in the area were invited to join in. This enterprise stands as a pioneer in Argentina in terms of development of bio-artwork, always considering the apocalyptic perspective towards the actions of men over the environment.

The works display an integral approach centered on research, scholarship, strategy-building and the analysis of design in daily life. This system—cleverly articulating education, work and experimentation-has granted the team members access to the different types of techniques within various areas of professional implementation, as the training in aesthetics is permanently linked to the realm of ideas, and given that the development of activities oriented to perception and sensitivity have always carried an ethical assessment. Being fostered and led by an educational institution, these artistic, scientific and technical developments also aim at promoting the interrelation and harmony between two opposed worlds, granting spectators the possibility of discovering the beauty and the importance of the elements and phenomena, both natural and those created by men.

The itinerary proposed for Project Untitled has at its core, and as guiding force, to address environmental issues and protect the environment, matters that are clearly put forth in works such as "God of Weather” (2008), a videogame in which the player must control forces of nature by means of hand gestures; "Potabile” (2009), a facility representing the exploitation of water resources; "Floris Lupus" (2010), an interactive structure that presents the beauty of the wilderness as opposed to the intervention and destruction by men despite their intentions, operated through proximity sensors; "Edenia" (2010), a post-war scenario generated as of technological waste where natural elements are corrupted in favor of the transgenic; “Extinction Scenes, Resurgence Rituals" (2012), where in addition to inviting the spectator to approach the work in which urban waste intervened with graffiti is exhibited inside skeletons of dinosaurs signaling the end of the itinerary, he was also given a questionnaire with queries on his habits and routine-intended as an exercise of introspection-that accompanied the presentation of a book, a round table, a series of movies and music festivals, all aimed at raising awareness of the critical change that landscape undergoes vis-à-vis the relentless advancement of men.

In these pieces of work, among others, there has been a clear intent to explore the notion of nature under a new interpretation by the machine to enable coexistence of the artificial and the natural elements, raising the public's awareness of their sensory exploration.

As of this experience, it is possible to coincide with Nicolás Bourriaud when he states,

If we carefully observe the contemporary artistic practices, we should talk about "formations" rather than "forms", the opposite of an object in utter seclusion due to a particular style or signature. Current artwork shows that form is only plausible in the encounter, in the dynamic relation that any artistic proposal holds with other formations, whether artistic or not. (2013, pp. 22-23) 
For this artistic ensemble, not just as creators of artwork, but as a pedagogical project oriented to the development of artists, the works have acquired a real dimension and existence, as different types of human interventions are put at play to engage in constant dialogue about current affairs and the various issues human beings must face.

In this sense and as a result of the dialogue stemmed from the interaction of the individuals directly involved in the creation of the work, those invited to join in, and the spectators, a new form of reconciliation derived, indeed, from the experience.

This experimentation, many times unconscious on the part of the spectator, has had repercussions in the way he perceives the world and the issues previously mentioned. Contrary to what happened centuries ago, when art also played an educational role that could only be grasped by the artistic genius, current works and artistic devices have placed an array of strategies and technical developments at the service of society, stemming from extremely rudimentary to highly complex elements, which have allowed individuals to own artistic models present in the works of technological art at a small scale and incorporate them into daily life.

Thus, art has also granted visibility to certain technical strategies for these to aid in the future development of goods, both for consumption and service, for reproduction or for reinsertion in the natural environment.

Increasingly, the artist needs to be thought of as a skilled worker integrated to production teams—-demands of the new ways of production exceed in many cases the idea of works produced by one single individual in the solitude of his workspace. And increasingly as well, his is a task of collective realization, in which the ownership is distributed within the team and even in the flow of circulation and exchange in which each and every participant is an intertextual modifier... (Brea, 2003, p. 50)

\section{Conclusion: Art as a Revolution and Consciousness}

As of the above mentioned, works of art presented through participatory events call for a certain type of awareness and knowledge on the part of the spectator, as of the willing negotiation and the exchange of time and space, of the acknowledgement of what he perceives as artwork.

"Spectators give form to the artwork", states Duchamp. Changes in the twentieth century drastically altered the traditional concept of artistic fact along with the traditional concept of spectator.

As Theodor Adorno claims,

It has become clear that nothing regarding art is evident: not in itself, not in its relationship with totality, not even in its right to exist. In art everything has become possible, the door has been opened to infinity and reflection has to deal with that. (1983, p. 192)

Following this line of thought, it is possible to say that the function of art is to be a sign of the times. In the era of interactivity, where it is possible to access any artistic representation virtually, the fact that the spectator may be a fundamental part in the work creates the opportunity for this public to add individual competencies, theoretical, historic and technical training and information, in order to take in as many signifiers in the work as possible, being attuned with all the potential metaphors and allegories through every individual understanding and perception that may in turn enrich the experience by completing it.

In the same fashion, each concept, every piece of information, every new cultural and technological development, all allow for the individual who faces the artistic experience to take with him a sensory rapprochement that fixes the message created by the artist in the memory. 
The artistic revolution of this time and age takes place in the encounter with this spectator avid of interaction, of participation, who claims for a main role through action.

In the fusion of science, technology and art, the spectator becomes aware mainly of how his actions both on ecosystems and on any environment, controlled or not, cannot go unnoticed. The lasting impact of his actions calls for reflection on the care and protection of resources currently at risk.

The future challenge is to educate a spectator that as of his intervention may be able to replicate the pieces of information, reflections and interactions experienced in his most immediate environment, reproducing interrelations with other individuals who, as in the case of these three spheres of knowledge, may work collaboratively to improve quality of life for all social stakeholders.

\section{References}

Adorno, T. (1983). Aesthetic theory. Madrid: Taurus.

Bourriaud, N. (1998/2006). Relational aesthetics. Buenos Aires: Adriana Hidalgo.

Brea, J. L. (2003). The third threshold. Murcia: Cendeac.

Eco, U. (1962/1992). Obra Abierta. Buenos Aires: Editorial Planeta.

Goodman, N. (1978/1990). World making ways. Madrid: La balsa de la medusa.

Jauss, H. R. (1986). Aesthetic experience and literary hermeneutics. Essays in the field of the aesthetic experience. Madrid: Taurus.

Jimenez, J. (1998). Beyond the aesthetic contemplation. Madrid: Fundación Argentaria.

Laddaga, R. (2010). Laboratory aesthetics. Strategies of current arts. Buenos Aires: Adriana Hidalgo.

Matewecki, N. (2012). Thinking intersections. (Unpublished)

Oliveras, E. (2006). Aesthetics. In The question of art. Buenos Aires: Ariel.

Oliveras, E. (2011). Issues on contemporary art-Towards the new spectator of century XXI. Buenos Aires: Planeta.

Proyecto Untitled. (2013). Art, science and technology (Proyecto untitled catalogue, Buenos Aires, Argentina).

Rancière, J. (2008/2010). The emancipated spectator. Buenos Aires: Manantial.

Suárez Guerrini, M. F., Gustavino, B., Correbo, M. N., \& Matewecki, N. (2010). Science uses in contemporary argentine art. Buenos Aires: Papers Publishers.

Tatarkiewicz, W. (1987/2001). History of six ideas. Madrid: Tecnos. 